\title{
IMPACTOS AGROCLIMÁTICOS PARA CULTURAS AGRÍCOLAS NO ESTADO DA PARAÍBA SOB CONDIÇÕES DE MUDANÇAS CLIMÁTICAS
}

\author{
AGROCLIMATIC IMPACTS FOR AGRICULTURAL CROPS IN THE STATE OF \\ PARAÍBA UNDER CONDITIONS OF CLIMATE CHANGE ${ }^{\circ}$ \\ IMPACTOS AGROCLIMÁTICOS PARA CULTURAS AGRÍCOLAS EN EL ESTADO DE \\ PARAÍBA SOB CONDICIONES DE CAMBIOS CLIMÁTICOS ${ }^{\circ}$
}

Recebido em: 17/11/2020 - Aprovado em: 06/01/2021 - Publicado em: 20/04/2021

d.

http://dx.doi.org/10.18011/bioeng2021v15n1p105-126

Amanda Fernandes Cândido' (amandafcandido@gmail.com)

Robson de Sousa Nascimento ${ }^{1}$ (robson.nascimento@academico.ufpb.br)

Valéria Peixoto Borges ${ }^{1}$ (valeria.borges@academico.ufpb.br)

1 Universidade Federal da Paraíba -UFPB, Centro de Ciências Agrárias, Campus II, Areia - PB, Brasil

RESUMO

O objetivo do trabalho foi realizar o zoneamento agroclimático para o estado da Paraíba tomando por base os cenários de mudanças climáticas do Painel Intergovernamental sobre Mudanças Climáticas (IPCC), para avaliar o impacto da demanda hídrica sobre a produção de cana-de-açúcar, milho e arroz, identificando e quantificando as áreas que são aptas, inaptas ou que possuem algumas restrições. Determinou-se o balanço hídrico climatológico e o índice de umidade utilizando dados meteorológicos de precipitação pluviométrica e temperatura média do ar das seis estações contidas no estado, referente ao período de 1981 a 2018. Para determinar a aptidão agroclimática das culturas foram utilizadas as faixas do índice de umidade. Constatouse que no cenário normal cerca de $7,6 \%$ e $10 \%$ da área do estado possui aptidão plena sem restrições e plena com período chuvoso prolongado respectivamente, para as três culturas. Em um cenário otimista, $7 \%$ da área do estado possui aptidão moderada por deficiência hídrica e 93\% inapta por deficiência hídrica. Já em um cenário pessimista, torna-se inviável o cultivo das culturas no estado em decorrência da drástica redução da disponibilidade hídrica para a região. Isto demonstra o quanto as mudanças climáticas podem impactar economicamente o estado da Paraíba, devendo serem criadas políticas de mitigação.

Palavras-chave: Cana-de-açúcar. Arroz. Milho. Balanço hídrico. Índice de umidade. Zoneamento agroclimático.

Artigo publicado sob a licença Creative Commons - Atribuição 4.0 Internacional (CC BY 4.0). 


\section{INTRODUÇÃO}

Os relatórios publicados pelo Painel Internacional sobre Mudanças Climáticas (IPCC), tem apontado que o clima da Terra está mudando, principalmente devido às ações antrópicas, causando elevação no nível do mar, na temperatura e irregularidades na distribuição espacial da precipitação (IPCC, 2007, 2014). Segundo SNIDERMAN et al. (2019), as regiões subtropicais do Hemisfério Sul apresentarão redução nos níveis de precipitação, aumentando a seca em determinadas regiões principalmente devido as ações antrópicas.

De acordo com o Painel Brasileiro de Mudanças Climáticas (PBMC, 2013) algumas regiões do Brasil poderão apresentar alterações na temperatura e precipitação com o aquecimento global, sendo que a Região Nordeste se apresenta como a mais vulnerável às mudanças climáticas devido as condições fisiográficas, climáticas e socioeconômicas. Ainda de acordo com o PBMC (2013), considerando um clima mais quente no futuro, o semiárido nordestino pode transformar-se em região árida, afetando, consequentemente, a agricultura de subsistência regional, a disponibilidade de água e a saúde da população, obrigando as mesmas a migrarem para outras regiões.

Um fator importante para determinar a disponibilidade hídrica de um determinado local, principalmente em cenários de mudanças climáticas, é o Balanço Hídrico Climatológico. MATOS et al. (2014) descrevem o balanço hídrico climatológico de uma região como uma variável relevante, pois considera a textura do solo, profundidade efetiva e o movimento de água no solo durante todo o ano (ano civil).

A técnica do balanço hídrico $(\mathrm{BH})$ fornece o saldo de água disponível no solo para o vegetal, contabilizando a entrada (precipitação e/ou irrigação) e a saída (evapotranspiração potencial), levando em consideração a capacidade de armazenamento de água pelo solo, servindo assim de subsídio para a escolha de culturas adaptadas a uma determinada condição climática predominante (MEDEIROS et al., 2013).

O BH é sensível à fatores como a quantidade de $\mathrm{CO} 2$ atmosférico, onde simulações indicaram que o seu aumento produz aumento no déficit hídrico (JESUS et al., 2017), indicando mudanças na temperatura e precipitação, fatores que controlam o $\mathrm{BH}$. O BH é bastante utilizado no Brasil para identificar a disponibilidade hídrica de um determinado local, bem como a classificação climática do mesmo, como mostram os trabalhos de PASSOS et al. (2017), OLIVEIRA \& OLIVEIRA (2018) e MATOS et al., (2020). 
Por outro lado, quando é preciso agrupar informações que auxiliem no planejamento de uma determinada região para se obter maior produção agrícola, recorre-se ao Zoneamento Agroclimático. $\mathrm{O}$ zoneamento agroclimático caracteriza-se pela espacialização de informações combinadas acerca das exigências agroclimáticas das culturas e das condições macroclimáticas do local. Por meio dessa técnica é possível delimitar as áreas propícias ou não para o cultivo de determinada espécie de interesse agrícola e estabelecer a melhor época de semeadura (MONTEIRO, 2009), como mostram os trabalhos de PANDOLFO et al. (2017) para o mirtilo, de MACHADO et al. (2017) para o melão e de SOUZA et al. (2018), para a palma forrageira.

O estado da Paraíba apresenta boa parte do território inserido no domínio climático do Semiárido, caracterizado por baixas e concentradas precipitações e alta demanda evaporativa. Diante dos cenários de mudanças climáticas, que apontam aumento da temperatura do ar e, consequentemente maior evapotranspiração, a agricultura no estado torna-se uma atividade ainda mais vulnerável. Estudos sobre a viabilidade hídrica são importantes para subsidiar ações de planejamento e alocação da água, considerando as projeções de mudanças no clima.

Assim, o presente trabalho tem por objetivo realizar o zoneamento agroclimático para o estado da Paraíba sob Cenários de futuras Mudanças Climáticas para avaliar o impacto da demanda hídrica sobre a produção de cana-de-açúcar, milho e arroz no Estado da Paraíba, identificando as áreas que são aptas, inaptas ou que possuem algumas restrições, quantificando essas áreas que foram impactadas. Foi feita a escolha dessas culturas por serem as três culturas com maior produção no Estado da Paraíba.

\section{MATERIAIS E MÉTODOS}

\section{1 ÁREA DE ESTUDO}

O Estado da Paraíba está localizado na região Nordeste do Brasil, apresentando uma área de 56.467,239 km² de acordo com o IBGE (2018). O Estado da Paraíba apresenta quatro tipos diferentes de clima, como é apresentado na Figura 1. O primeiro é o clima Aw que caracteriza a região como Tropical, com estação seca no inverno. O segundo tipo climático é o clima Am, que é característico de regiões monçônicas e está relacionado a regiões de alto volume anual de precipitação. O terceiro tipo climático da Paraíba é o As, que, em sua maioria, pertencem às regiões que fazem parte do Litoral, Brejo, Agreste em 
pequena faixa da região do Sertão e em toda área do Alto Sertão. E por fim, o clima Bsh, que se estende por todo Planalto da Borborema, sendo também predominante da região do Cariri/Curimataú e parte do Sertão.

Figura 1 - Classificação climática de Köppen para o estado da Paraíba.

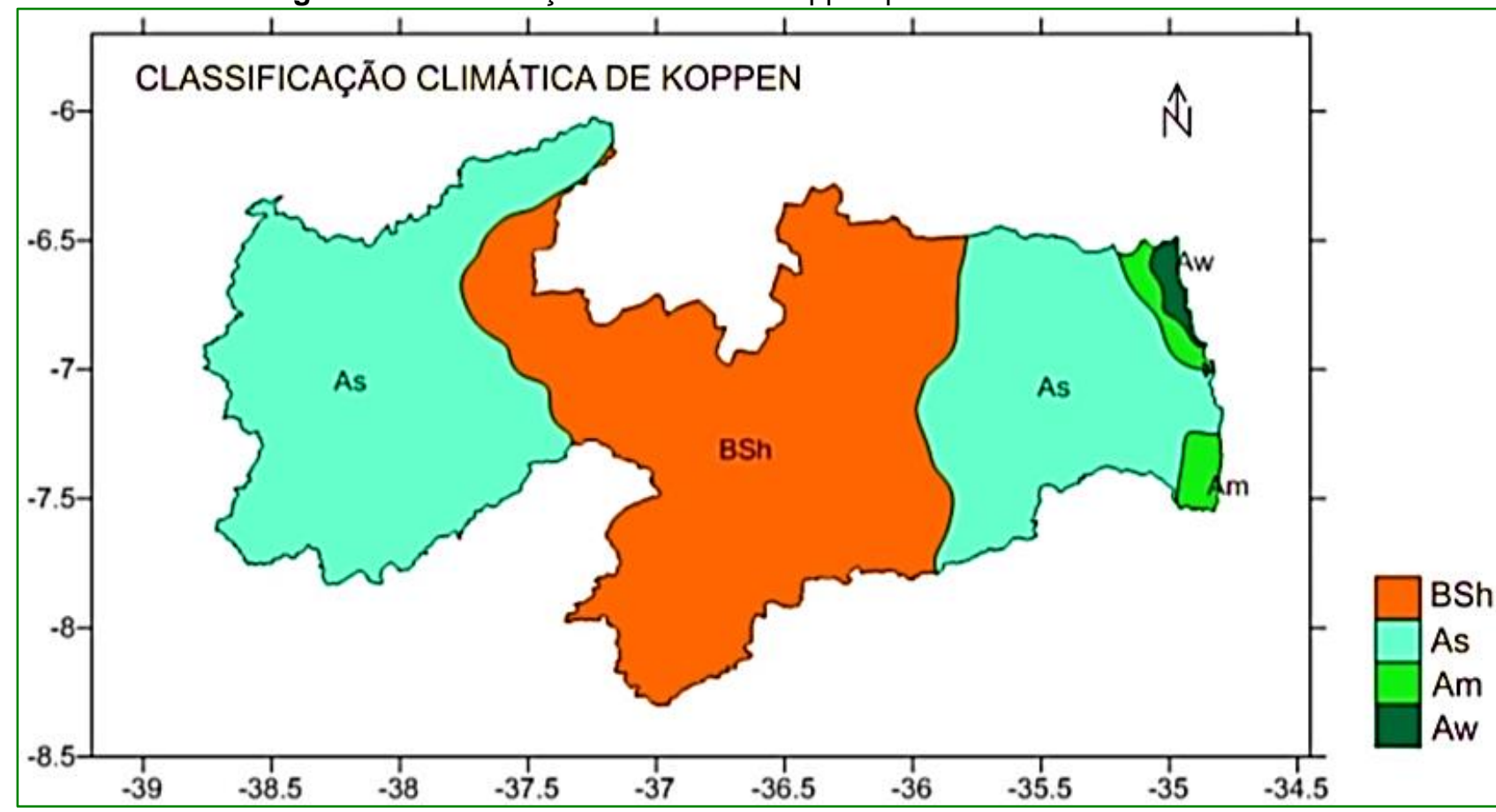

Fonte: FRANCISCO et al., (2015).

O estado caracteriza-se por dois regimes de chuvas, um de fevereiro a maio, nas regiões do Alto Sertão, Sertão e Cariri/Curimataú; e o outro de abril a julho, no Agreste, Brejo e Litoral (FRANCISCO \& SANTOS, 2017). Segundo NOBREGA et al. (2014), o estado da Paraíba está dividido em quatro mesorregiões distintas: Mata Paraibana, Agreste Paraibano, Borborema e Sertão Paraibano, como ilustra a Figura 2. 
Figura 2 - Mesorregiões da Paraíba. Fonte: AESA (2020).

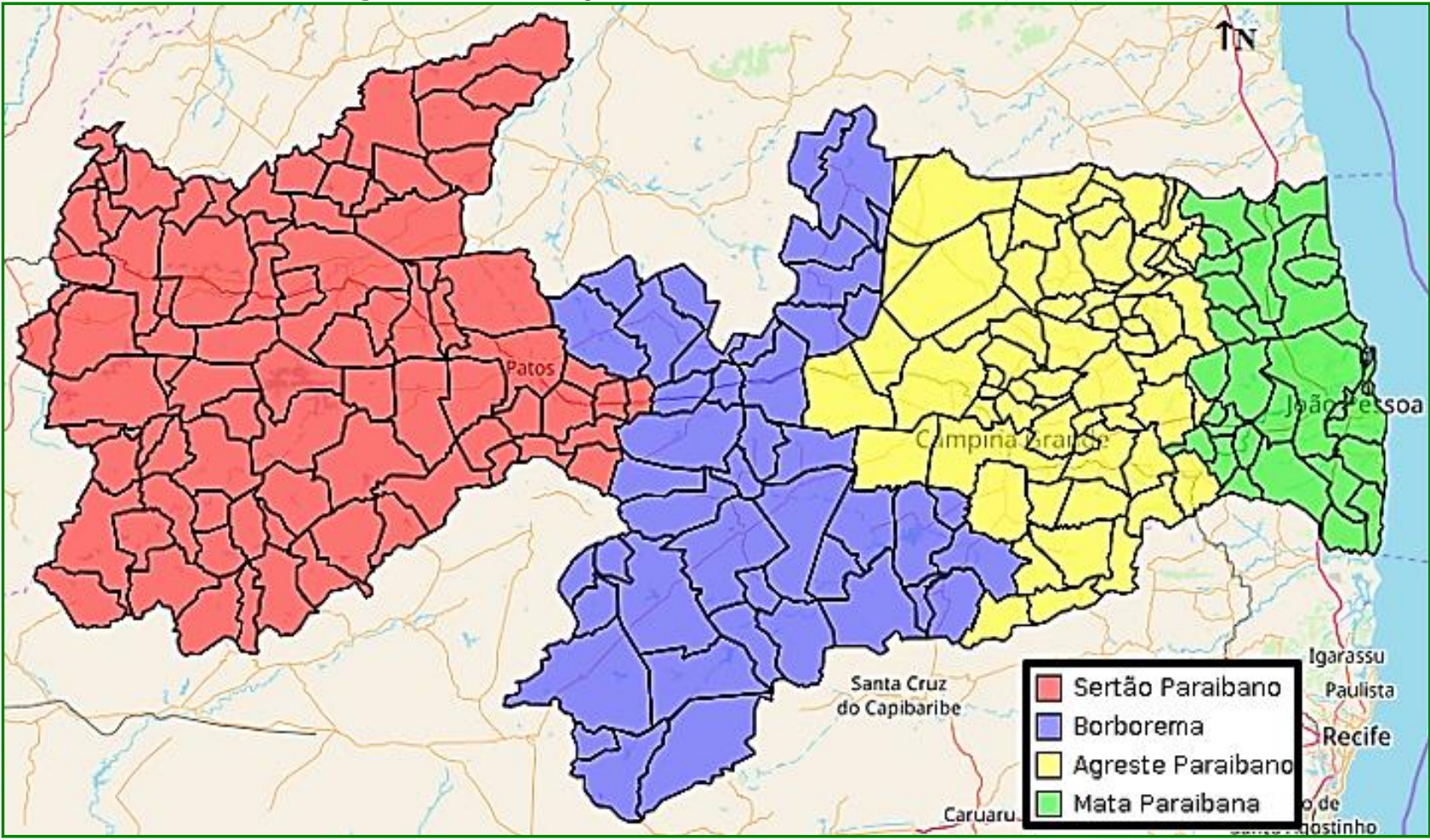

Fonte: AESA (2020).

Os dados de precipitação e temperatura utilizados no presente estudo foram provenientes do Instituto Nacional de Meteorologia (www.portal.inmet.gov.br), referentes as seis estações meteorológicas contidas no estado, como mostra a Tabela 1. Os dados são da normal climatológica de 1981 a 2018, totalizando 37 anos.

Tabela 1 - Dados meteorológicos.

\begin{tabular}{lllllll}
\hline Estações & & \multirow{2}{*}{ Latitude $\left(^{\circ}\right)$} & Longitude $\left(^{\circ}\right)$ & Altitude $(\mathrm{m})$ & Temperatura $\left({ }^{\circ} \mathrm{C}\right)$ & Precipitação \\
Meteorológicas & Lañ & Máx. & $(\mathrm{mm})$ \\
\hline Areia & $-6,98$ & $-35,72$ & 571,75 & 19,96 & 27,44 & 1255,26 \\
Campina Grande & $-7,22$ & $-35,9$ & 546,27 & 19,94 & 29,04 & 729,17 \\
João Pessoa & $-7,1$ & $-34,85$ & 9,67 & 24,05 & 30,47 & 1825,97 \\
Monteiro & $-7,89$ & $-37,12$ & 606,41 & 18,79 & 31,76 & 569,56 \\
Patos & $-7,05$ & $-37,27$ & 251,65 & 22,25 & 34,58 & 604,42 \\
São Gonçalo & $-6,84$ & $-38,31$ & 237,04 & 21,80 & 34,00 & 841,38 \\
\hline
\end{tabular}

Fonte: Normais Climatológicas do Instituto Nacional de Meteorologia. 


\subsection{CULTURAS AGRÍCOLAS}

As culturas escolhidas para este trabalho foram as que apresentaram maiores índices de produção no estado da Paraíba no ano de 2018, sendo elas: o arroz, a cana-deaçúcar e o milho.

Segundo dados da Conab, a cultura do arroz apresentou produção nacional de 10,4 milhões de toneladas na safra 2018/19 com maior concentração na Região Sul, responsável por $82,7 \%$ da oferta nacional. Na Paraíba a área total foi de 1,1 mil hectares com produção de 1,2 mil toneladas. A cana-de-açúcar no estado ocupou uma área total de 134,2 mil hectares na safra 2018/19, incluindo as destinadas à mudas, a área plantada para colheita foi de 122,1 mil hectares com produção de $5.589,1$ mil toneladas. Os números do milho para mesma safra foram de 102,8 mil hectares, com produção de 64,1 mil toneladas.

\subsection{CENÁRIOS CLIMÁTICOS}

Os cenários para os quais foram utilizados os dados de temperatura e precipitação foram baseados no quinto relatório do IPCC (IPCC, 2014), em que definem os cenários RCP4.5, antigo cenário otimista no AR4, em que apresenta um aumento na temperatura de até $3{ }^{\circ} \mathrm{C}$ até o final do século, e RCP8.5, antigo cenário pessimista no AR4, onde a temperatura apresentaria um aumento de $4,5^{\circ} \mathrm{C}$ até o final do século. Para as projeções no Estado da Paraíba foi tomado por base o Relatório de Clima do INPE (INPE, 2009) onde apresenta estes valores de temperatura e precipitação para os futuros cenários de mudanças climáticas para a região nordeste do Brasil. Desse modo, levou-se em consideração um aumento na temperatura de $1,4{ }^{\circ} \mathrm{C}$ e redução de $15 \%$ na precipitação para o cenário $\mathrm{RCP} 4.5$, e aumento na temperatura de $4,0 \stackrel{\circ}{ } \mathrm{C}$ e redução na precipitação de $20 \%$ para o cenário RCP8.5.

\subsection{BALANÇO HÍDRICO CLIMATOLÓGICO}

Utilizou-se o método de THORNTHWAITE \& MATHER (1955) para calcular o balanço hídrico climatológico $(\mathrm{BHC})$ de cada localidade onde as estações meteorológicas estão situadas, considerando a capacidade média de armazenamento de água no solo (CAD) de acordo com as portarias que regulamentam o zoneamento agrícola de risco climático (ZARC) para cada cultura no estado. Desse modo, foi tomado como valores da 
CAD do solo os valores de $75 \mathrm{~mm}, 50 \mathrm{~mm}$ e $40 \mathrm{~mm}$ para cana-de-açúcar, arroz e milho respectivamente (MAPA, 2010, 2016, 2018).

Para tanto, foram utilizados alguns parâmetros, como o déficit hídrico (D), excedente hídrico (E), o índice hídrico ( $\mathrm{I}_{\mathrm{h}}$ ), o índice de umidade ( $\mathrm{l}_{\mathrm{u}}$ ) e o índice de aridez ( $\mathrm{I}_{\mathrm{a}}$ ). Esses parâmetros foram determinados para determinar a aptidão das culturas em estudo.

\subsection{CRITÉRIOS PARA APTIDÃO CLIMÁTICA}

A avaliação da aptidão climática das culturas foi realizada utilizando os critérios e a metodologia adaptada pela EMBRAPA (2012), onde o índice efetivo de umidade (lu) foi utilizado como parâmetro.

O índice de umidade $\left(I_{U}\right)$ é dado por:

$I_{u}=I_{h}-I_{a}(1)$

Onde $I_{h}$ é o índice hídrico, que é dado por:

$I_{h}=\frac{100 E}{E T P}(2)$

O índice de aridez, $l_{a}$, é dado por:

$I_{a}=\frac{100 D}{E T P}(3)$

Sendo que o excedente hídrico (E), a evapotranspiração potencial (ETP) e o déficit hídrico (D) são dados em milímetros ( $\mathrm{mm}$ ).

Os requerimentos para cada aptidão climática são apresentados na Tabela 2.

Tabela 2 - Avaliação de aptidão climática das culturas.

\begin{tabular}{ll}
\hline Aptidão Climática & Índice de umidade (lu) \\
\hline Moderada por excesso hídrico (MEH) & $\mathrm{lu} \geq 40$ \\
Plena com período chuvoso prolongado (PCP) & $10<\mathrm{lu} \leq 40$ \\
Plena sem restrição (PSR) & $0<\mathrm{lu} \leq 10$ \\
Moderada por deficiência hídrica (MDH) & $-10<\mathrm{lu} \leq 0$ \\
Inapta por deficiência hídrica acentuada (IDH) & $\mathrm{lu} \leq-10$ \\
\hline
\end{tabular}

Fonte: EMBRAPA (2012) 
Os índices determinados para cada localidade foram aplicados para obter os mapas de aptidão climática atual e nos cenários de mudança climática para cada cultura no Estado da Paraíba. Para tanto, utilizou-se a versão gratuita do software Surfer para realizar a interpolação e mapeamento pelo método da Krigagem. O mapa contorno do estado foi feito em Sistema de Coordenadas Geográficas, Datum Sirgas 2000.

\section{RESULTADOS E DISCUSSÃO}

\subsection{ARROZ}

No estado da Paraíba o arroz é cultivado no sistema de sequeiro, que, de acordo com SILVA et al. (1995), é considerado de alto risco climático, basicamente por ser extremamente dependente da oferta pluvial e pela ocorrência de estiagens prolongadas.

Os componentes climáticos que favorecem o crescimento e a qualidade da produção da cultura do arroz bem como para as demais culturas estudadas no estado são apresentados na Tabela 3 .

Tabela 3 - Requerimentos climáticos.

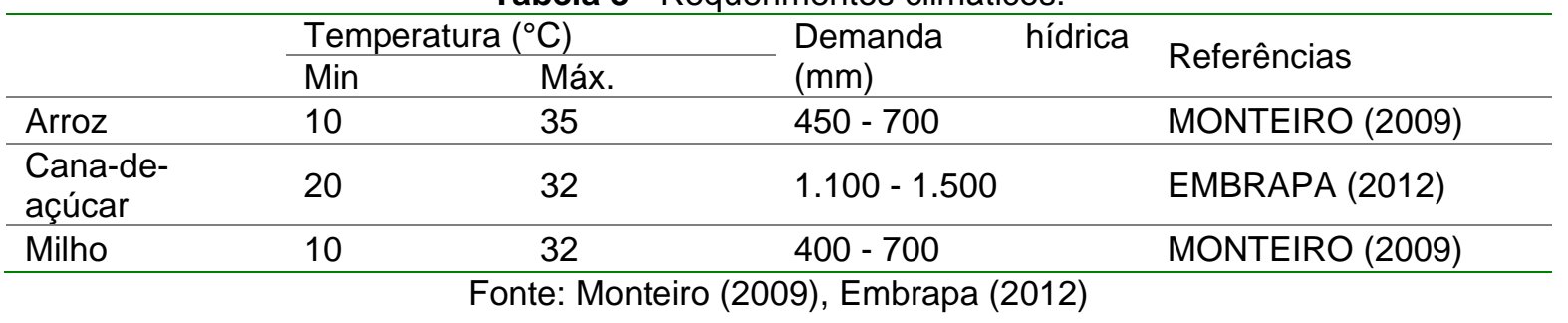

O índice de umidade relaciona os índices hídricos e de aridez. Na Figura 3, a distribuição espacial mostra que os maiores valores no índice de umidade foram registrados na região litorânea, no entanto nos cenários otimista e pessimista verificou-se apenas valores negativos, inclusive na região referida.

A Figura 4 apresenta o zoneamento agroclimático da cultura do arroz no estado para a capacidade de água disponível no solo de $50 \mathrm{~mm}$. No cenário normal observa-se as classes de aptidão plena sem restrições (PSR) e plena com período chuvoso prolongado (PCP) abrangendo áreas do Agreste e Mata Paraibana ocupando 7,6 e 10,06 \% de toda área do estado (Tabela 4) com 4.338,02 km² e 5.680,65 km², respectivamente. 
Figura 3 - Índice de umidade para a cultura do arroz no Estado da Paraíba, Brasil, na condição atual (Normal) e nos cenários Otimista e Pessimista das projeções de mudanças climáticas.

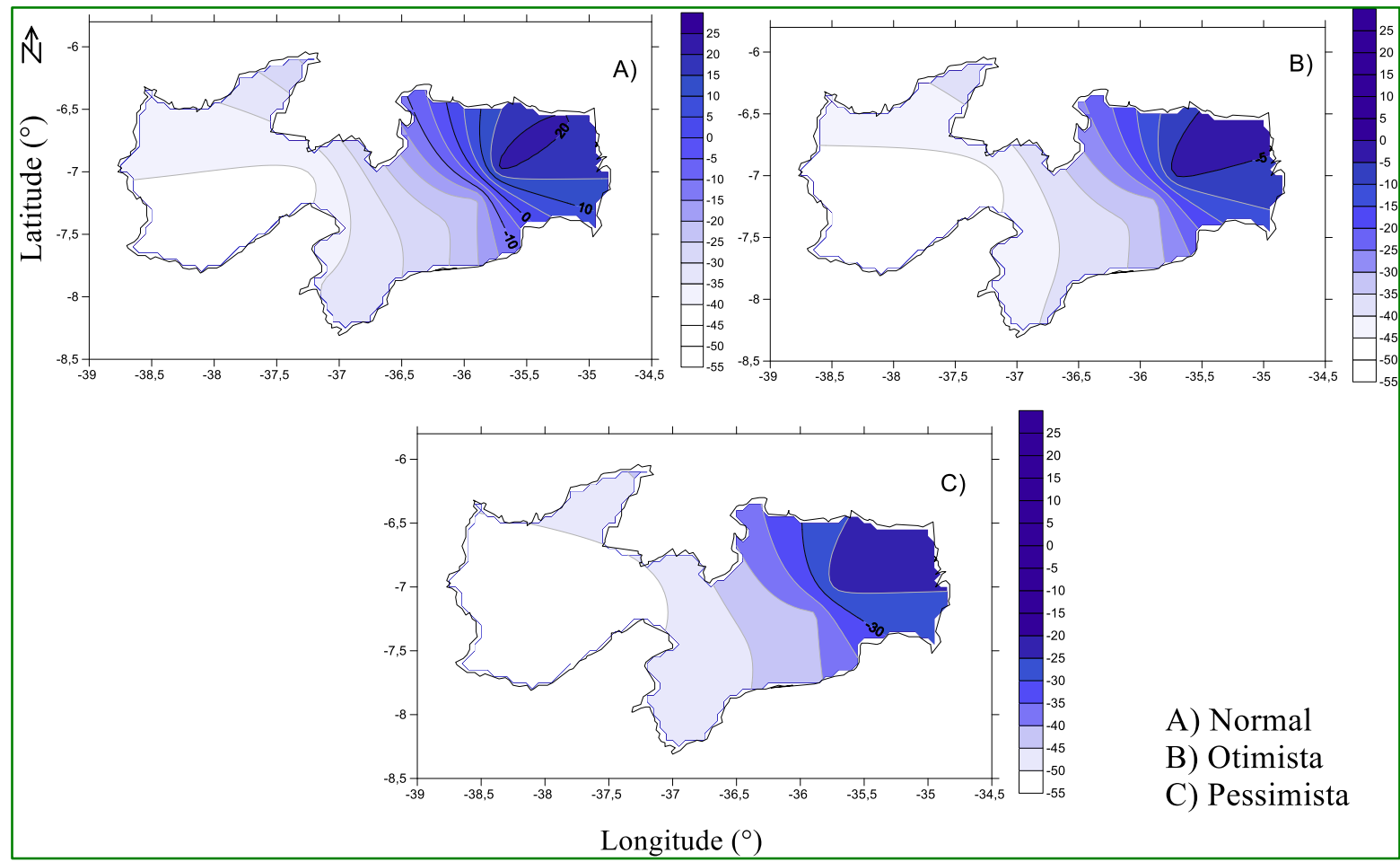

Fonte: Elaborado pelos próprios autores

Observa-se também as classes moderada por deficiência hídrica (MDH) que abrange o Agreste Paraibano, e ocupa uma área de 3.278,16 km², representando 5,81\% de toda área do estado. A inapta por restrição hídrica (IDH) ocupa a maior parte da área do estado, cerca de 76,45 \%, com 43.170,40 km² e abrange as mesorregiões da Borborema e Sertão Paraibano.

Tabela 4. Extensão territorial das classes de aptidão climática do arroz.

\begin{tabular}{|c|c|c|c|c|c|c|c|}
\hline \multirow{3}{*}{ Legenda } & \multirow{3}{*}{ Aptidão Climática } & \multicolumn{6}{|c|}{ Cenários } \\
\hline & & \multicolumn{2}{|c|}{ Normal } & \multicolumn{2}{|c|}{ Otimista } & \multicolumn{2}{|c|}{ Pessimista } \\
\hline & & $\mathrm{km}^{2}$ & $\%$ & $\mathrm{~km}^{2}$ & $\%$ & $\mathrm{~km}^{2}$ & $\%$ \\
\hline PSR & $\begin{array}{l}\text { Plena sem } \\
\text { restrição }\end{array}$ & $4.338,02$ & 7,68 & 0,00 & 0,00 & 0,00 & 0,00 \\
\hline PCP & $\begin{array}{c}\text { Plena com período } \\
\text { chuvoso } \\
\text { prolongado }\end{array}$ & $5.680,65$ & 10,06 & 0,00 & 0,00 & 0,00 & 0,00 \\
\hline MEH & $\begin{array}{l}\text { Moderada por } \\
\text { excesso hídrico }\end{array}$ & 0,00 & 0,00 & 0,00 & 0,00 & 0,00 & 0,00 \\
\hline MDH & $\begin{array}{c}\text { Moderada por } \\
\text { deficiência hídrica }\end{array}$ & $3.278,16$ & 5,81 & $3.959,97$ & 7,01 & 0,00 & 0,00 \\
\hline IDH & $\begin{array}{c}\text { Inapta por } \\
\text { deficiência hídrica }\end{array}$ & $43.170,4$ & 76,45 & $52.507,27$ & 92,99 & $56.467,24$ & 100 \\
\hline
\end{tabular}

Fonte: Elaborado pelos próprios autores 
Figura 4. Aptidão climática para a cultura do arroz no Estado da Paraíba, Brasil, na condição atual (Normal) e nos cenários Otimista e Pessimista das projeções de mudanças climáticas. PSR= Plena sem restrição; $\mathrm{PCP}=$ Plena com período chuvoso prolongado; $\mathrm{MEH}=$ Moderada por excesso hídrico; $\mathrm{MDH}=$ Moderada por deficiência hídrica; IDH= Inapta por deficiência hídrica acentuada.

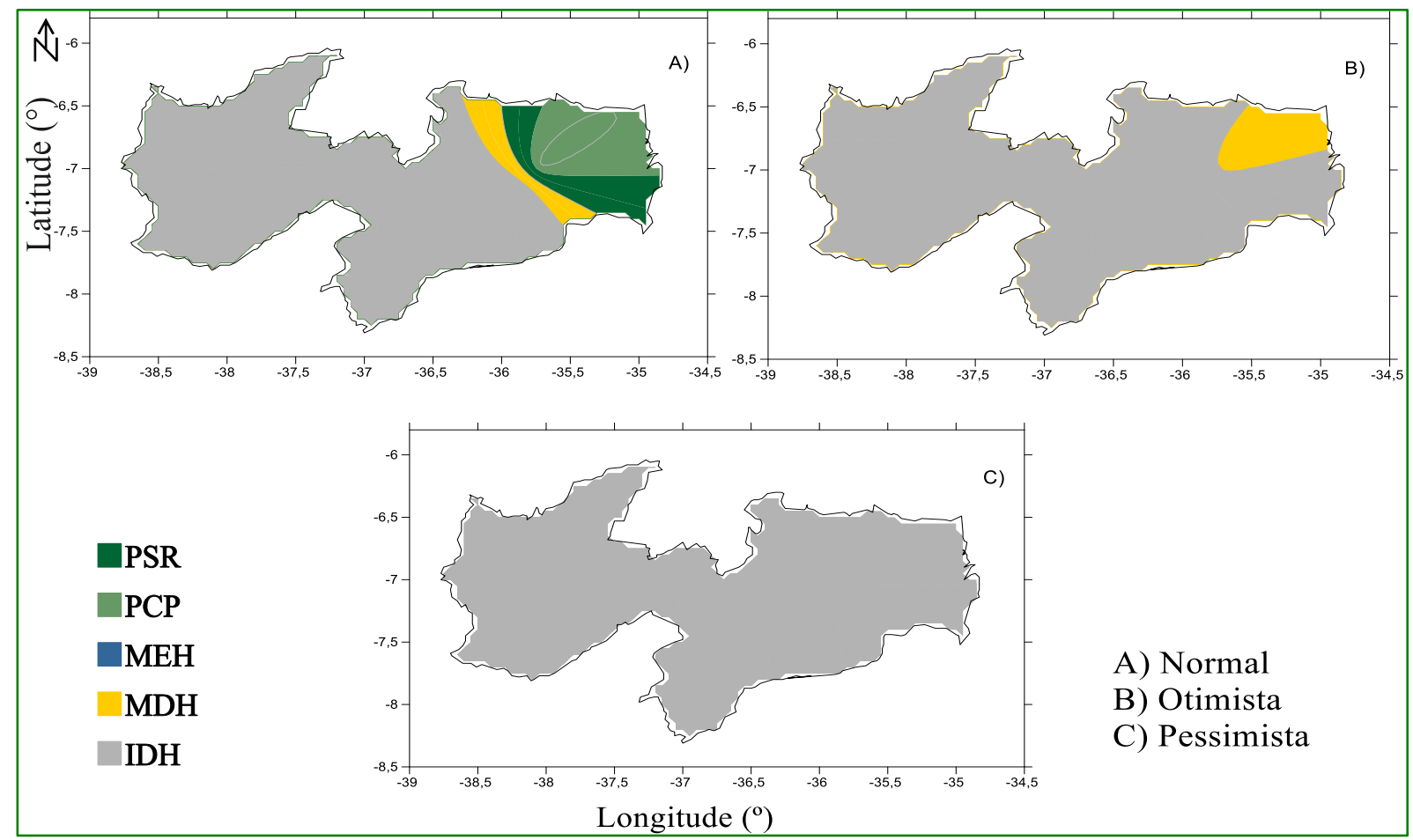

Fonte: Elaborado pelos próprios autores

No cenário otimista observa-se o deslocamento da classe moderada por deficiência hídrica $(\mathrm{MDH})$ para a região mais litoral do estado, ou seja, na mesorregião Mata Paraibana passando a ocupar uma área de 3.959,97 km², que abrange cerca de 7,01\% da área total. E o aumento da classe inapta por restrição hídrica (IDH) para 52.507,27 km², ocupando cerca de $92,99 \%$ da área do estado.

Considerando o cenário de mudanças climáticas pessimista, a classe inapta por restrição hídrica (IDH) passa a abranger todo o estado inviabilizando o cultivo do arroz.

Em toda área do estado não foram observadas áreas com aptidão climática da classe Moderada por excesso hídrico $(\mathrm{MDH})$ em nenhum dos três cenários.

MACHADO (1996) citado por CARVALHO et al. (2013) relata que a falta de água causa vários distúrbios fisiológicos às plantas de arroz, que são evidenciados diretamente no rendimento final. Ainda de acordo o autor, essa deficiência hídrica afeta trocas gasosas das plantas com o ambiente, alteram o comportamento na concentração de $\mathrm{CO}_{2}$ e a época 
de ocorrência desse estresse incide sobre a produção de fitomassa pelas plantas, influenciando economicamente a atividade.

\subsection{CANA-DE-AÇÚCAR}

A distribuição espacial do índice de umidade para a cana-de-açúcar (Figura 5), mostra que os maiores valores foram registrados na região litorânea, no entanto nos cenários otimista e pessimista verificou-se apenas valores negativos inclusive na região referida.

A Figura 6 ilustra as áreas aptas para o cultivo da cana de açúcar no estado considerando a capacidade de armazenamento de água no solo de $75 \mathrm{~mm}$.

No cenário normal observa-se as classes de aptidão plena sem restrições (PSR) e plena com período chuvoso prolongado (PCP) abrangendo áreas do Agreste e Mata Paraibana ocupando 7,6 e 9,52 \% de toda área do estado (Tabela 5) com 4.292,53 km² e $5.374,49 \mathrm{~km}^{2}$, respectivamente.

Figura 5 - Índice de umidade para a cultura da cana-de açúcar no Estado da Paraíba, Brasil, na condição atual (Normal) e nos cenários Otimista e Pessimista das projeções de mudanças climáticas.

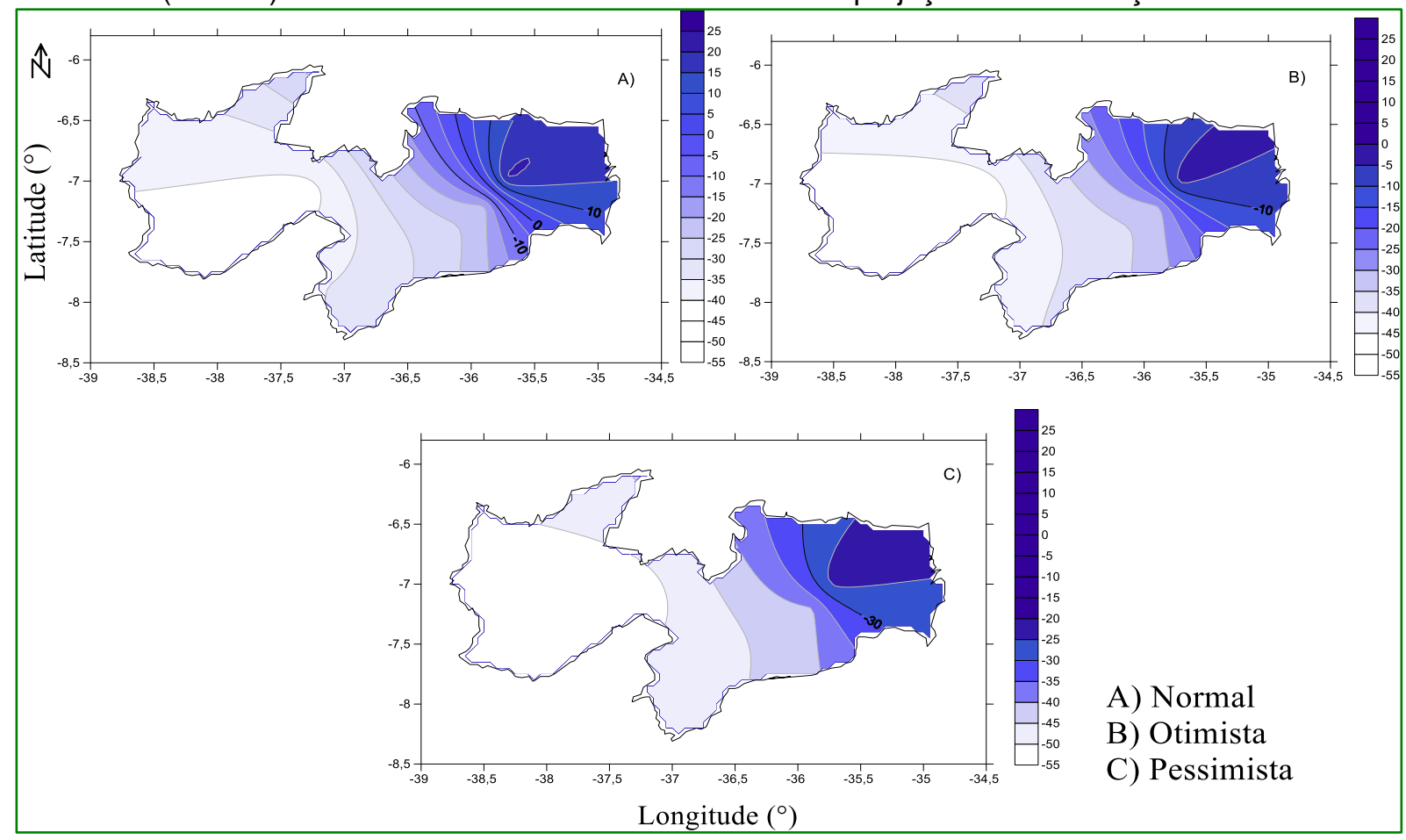

Fonte: Elaborado pelos próprios autores 
Figura 6 - Aptidão Climática para a cultura da cana-de-açúcar no Estado da Paraíba, Brasil, na condição atual (Normal) e nos cenários Otimista e Pessimista das projeções de mudanças climáticas. PSR= Plena sem restrição; $\mathrm{PCP}=$ Plena com período chuvoso prolongado; $\mathrm{MEH}=$ Moderada por excesso hídrico; $\mathrm{MDH}=$ Moderada por deficiência hídrica; IDH= Inapta por deficiência hídrica acentuada.

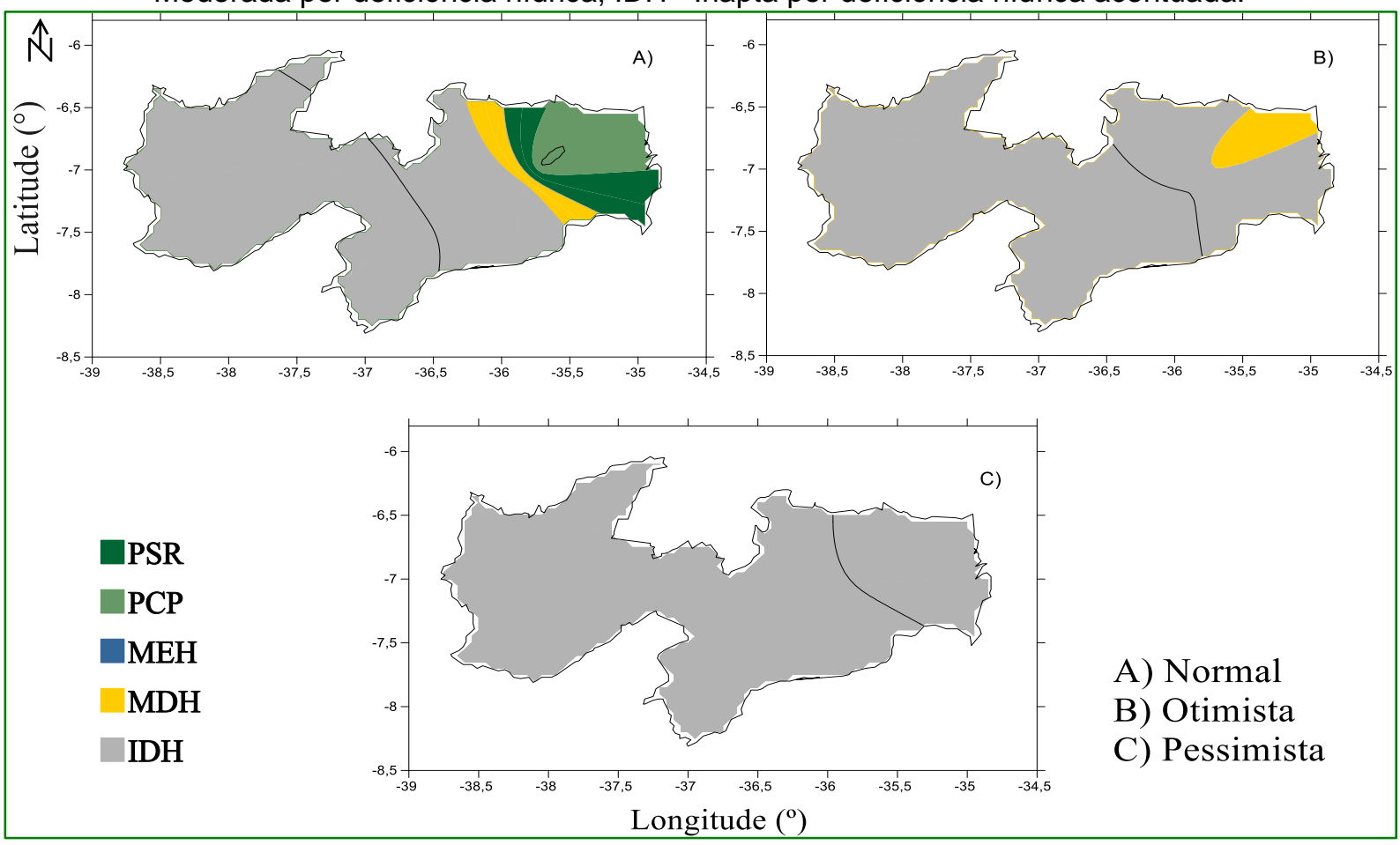

Fonte: Elaborado pelos próprios autores

Tabela 5. Extensão territorial das classes de aptidão climática da cana-de-açúcar

\begin{tabular}{|c|c|c|c|c|c|c|c|}
\hline \multirow{3}{*}{ Legenda } & \multirow{3}{*}{ Aptidão Climática } & \multicolumn{6}{|l|}{ Cenários } \\
\hline & & \multicolumn{2}{|l|}{ Normal } & \multicolumn{2}{|l|}{ Otimista } & \multicolumn{2}{|l|}{ Pessimista } \\
\hline & & $\mathrm{km}^{2}$ & $\%$ & $\mathrm{~km}^{2}$ & $\%$ & $\mathrm{~km}^{2}$ & $\%$ \\
\hline PSR & $\begin{array}{ll}\text { Plena } & \text { sem } \\
\text { restrição } & \\
\end{array}$ & $4.292,53$ & 7,60 & 0,00 & 0,00 & 0,00 & 0,00 \\
\hline PCP & $\begin{array}{l}\text { Plena com período } \\
\text { chuvoso } \\
\text { prolongado }\end{array}$ & $5.374,49$ & 9,52 & 0,00 & 0,00 & 0,00 & 0,00 \\
\hline MEH & $\begin{array}{l}\text { Moderada por } \\
\text { excesso hídrico }\end{array}$ & 0,00 & 0,00 & 0,00 & 0,00 & 0,00 & 0,00 \\
\hline MDH & $\begin{array}{l}\text { Moderada por } \\
\text { deficiência hídrica }\end{array}$ & $3.296,24$ & 5,84 & $3.621,01$ & 6,41 & 0,00 & 0,00 \\
\hline IDH & $\begin{array}{l}\text { Inapta por } \\
\text { deficiência hídrica }\end{array}$ & $43.503,97$ & 77,04 & $52.846,23$ & 93,59 & $56.467,24$ & 100 \\
\hline
\end{tabular}

Como relata a EMBRAPA (2012), se bem distribuída em um total de chuva entre $1.100 \mathrm{~mm}$ e $1.500 \mathrm{~mm}$ é adequado para a cultura, principalmente nos meses de crescimento vegetativo, seguido por um período relativamente mais seco de amadurecimento. Essas características foram observadas principalmente em Areia e João 
Pessoa, onde foram observados que os valores de precipitação atendem a necessidade da cultura, sendo 1825,97 mm em João Pessoa e 1255,56 mm em Areia.

Além da precipitação, as áreas apresentaram temperaturas que favorecem o aumento da taxa fotossintética, $22,54{ }^{\circ} \mathrm{C}$ em Areia e $27,09^{\circ} \mathrm{C}$ em João Pessoa. De acordo com FAUCONIER \& BASSEREAU, (1970) citado por EMBRAPA (2012), temperaturas entre $21^{\circ} \mathrm{C}$ e $32^{\circ} \mathrm{C}$ aumentam a taxa fotossintética.

Observou-se ainda no cenário normal que a classe moderada por deficiência hídrica (MDH), que abrange a região do Agreste onde situa-se Campina Grande, apresentou temperatura de $23,37^{\circ} \mathrm{C}$ e precipitação de $729,17 \mathrm{~mm}$, estando abaixo do valor adequado para a cultura mostrado acima. E a classe inapta por deficiência hídrica (IDH) abrange principalmente a região do Sertão Paraibano e da Borborema onde foram verificados os menores valores de precipitação e índices de umidade e os maiores valores de déficit hídrico.

No cenário otimista, observa-se o deslocamento da classe moderada por deficiência hídrica $(\mathrm{MDH})$ para a região mais litorânea do estado, ou seja, na mesorregião Mata Paraibana passando a ocupar uma área de $3.621,01 \mathrm{~km}^{2}$, cerca de $6,41 \%$ da área total. $E$ o aumento da classe inapta por restrição hídrica (IDH) para 52.846,23 km², ocupando 93,59 $\%$ da área do estado.

Considerando o cenário de mudanças climáticas pessimista, a classe passa a abranger todo o estado, inviabilizando o cultivo de cana-de-açúcar no estado.

Em todo o estado não foram observadas áreas com aptidão climática da classe Moderada por excesso hídrico (MDH) em nenhum dos três cenários. Francisco e Santos (2018) estudando a aptidão climática da cana-de-açúcar no estado relataram que 1.277,84 $\mathrm{km}^{2}$, representando $2,27 \%$ da área total do estado, possui plena aptidão para o cultivo, ocorrendo numa faixa entre o litoral norte e sul incluindo a capital do Estado, o município de João Pessoa.

A Embrapa, em estudo similar no estado de Alagoas, relata que deficiência hídrica em anos secos limita o cultivo da cana-de-açúcar em grande parte do Estado, principalmente na região Semiárida e Agreste, acarretando frequentemente a queda de produção, a restrição e morte de plantios em fase de renovação (EMBRAPA, 2012). 


\subsection{MILHO}

A Figura 7 ilustra a distribuição espacial do índice de umidade para o milho onde observa-se que os maiores valores foram registrados na região litorânea, no entanto nos cenários otimista e pessimista verificou-se apenas valores negativos inclusive na região referida.

A Figura 8, apresenta as áreas aptas para o cultivo de milho no estado considerando a capacidade de armazenamento de água no solo de $40 \mathrm{~mm}$. No cenário normal observase as classes de aptidão plena sem restrições (PSR) e plena com período chuvoso prolongado (PCP) abrangendo áreas do Agreste e Mata Paraibana ocupando 7,62 e 10,26 \% de toda área do estado (Tabela 6) com 4.305,44 km² e 5.794,71 km², respectivamente.

Observa-se também as classes moderada por deficiência hídrica (MDH) que abrange o Agreste Paraibano, e ocupa uma área de 3.260,65 km², representando 5,77\% de toda área do estado. A área inapta por restrição hídrica (IDH) ocupa a maior parte da área do estado cerca de $76,34 \%$ com $43.106,44 \mathrm{~km}^{2}$ e abrange $52.386,04 \mathrm{~km}^{2}$, ocupando cerca de $92,77 \%$ da área do estado.

Figura 7 - Índice de umidade para a cultura do milho no Estado da Paraíba, Brasil, na condição atual (Normal) e nos cenários Otimista e Pessimista das projeções de mudanças climáticas.

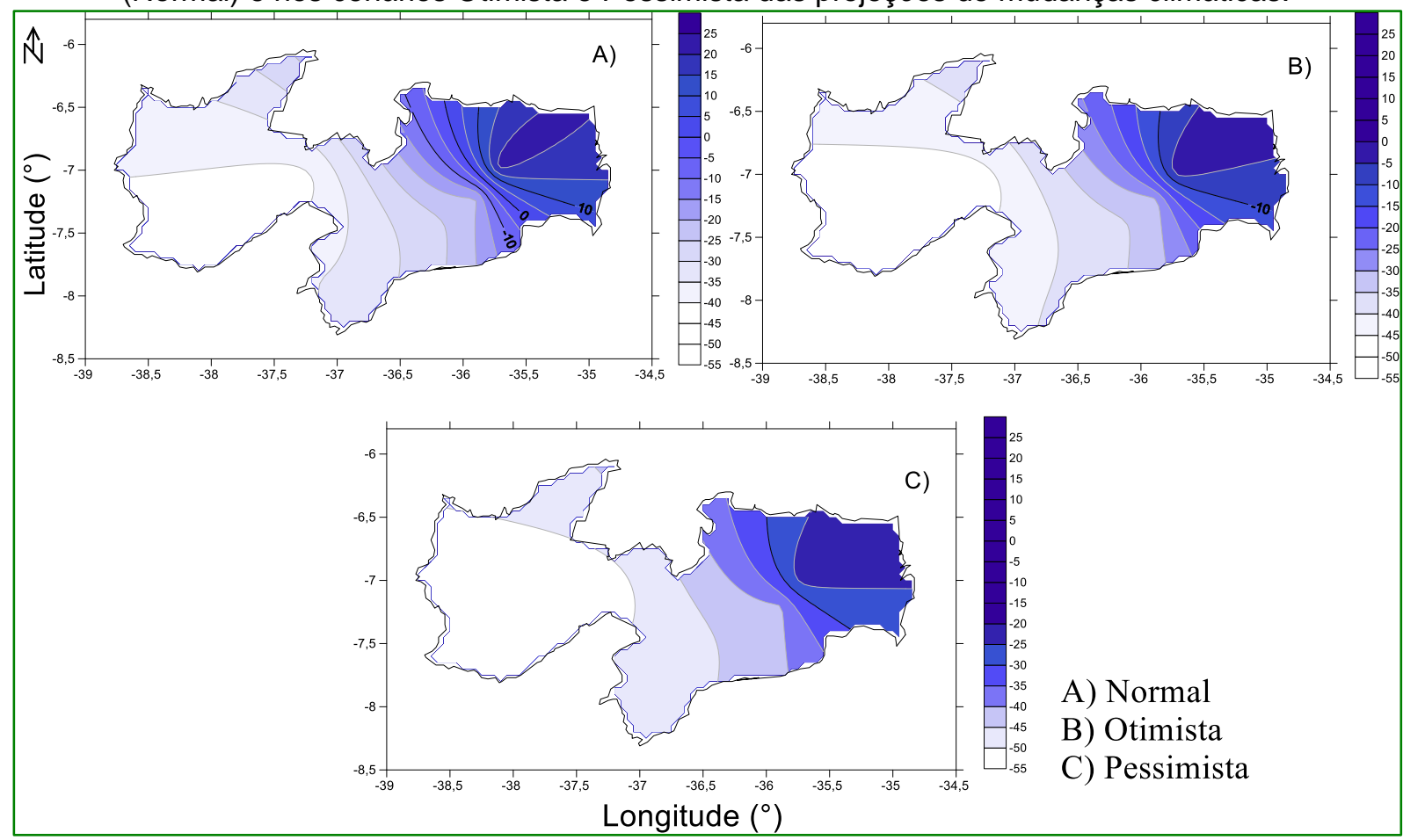

Fonte: Elaborado pelos próprios autores 
Figura 8. Aptidão Climática do milho. $\mathrm{PSR}=\mathrm{Plena}$ sem restrição; $\mathrm{PCP}=\mathrm{Plena}$ com período chuvoso prolongado; $\mathrm{MEH}=$ Moderada por excesso hídrico; $\mathrm{MDH}=$ Moderada por deficiência hídrica; IDH= Inapta por deficiência hídrica acentuada.

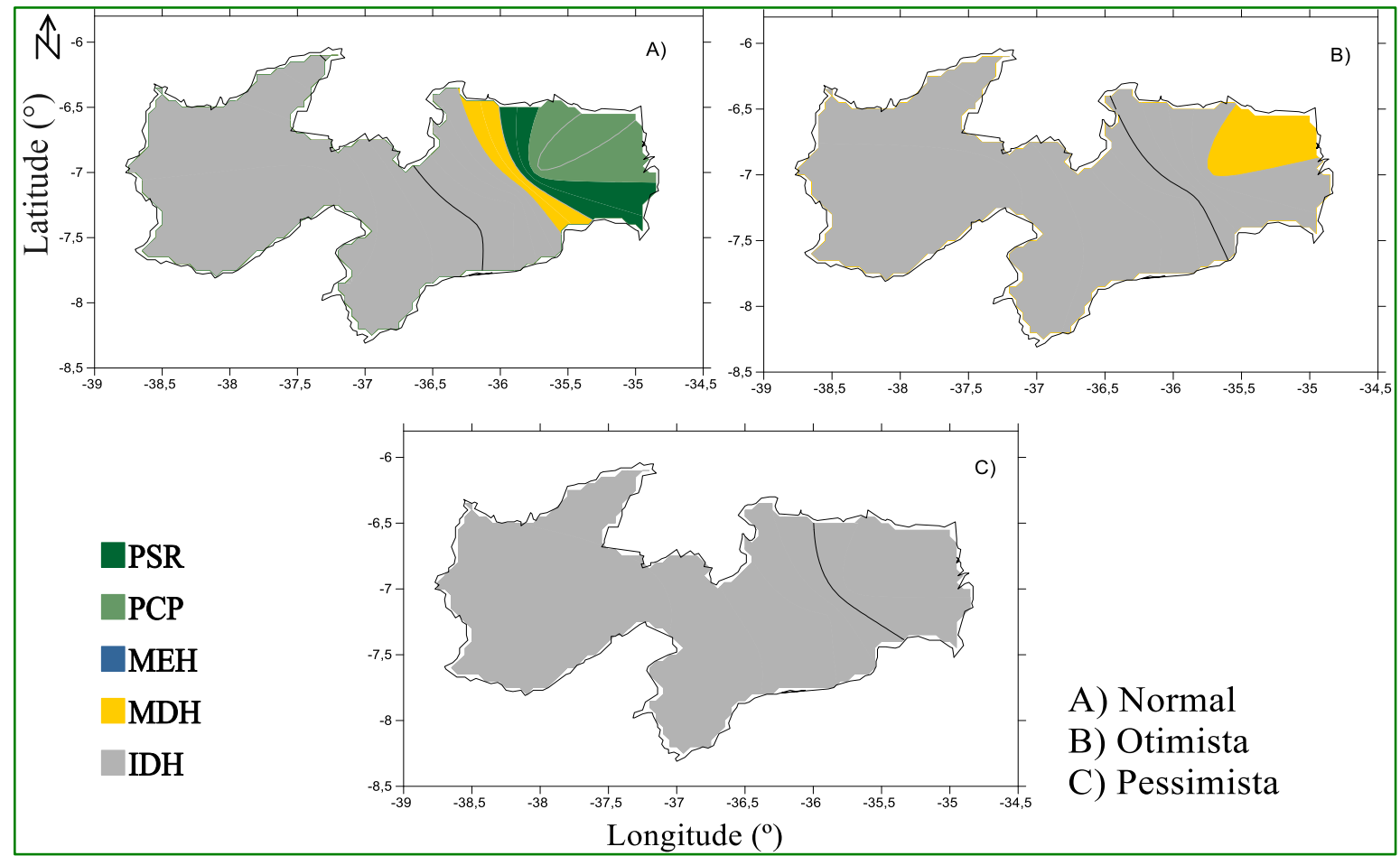

Fonte: Elaborado pelos próprios autores

Tabela 6. Extensão territorial das classes de aptidão climática do milho.

\begin{tabular}{|c|c|c|c|c|c|c|c|}
\hline \multirow{3}{*}{ Legenda } & \multirow{3}{*}{$\begin{array}{l}\text { Aptidão } \\
\text { Climática }\end{array}$} & \multicolumn{6}{|l|}{ Cenários } \\
\hline & & \multicolumn{2}{|l|}{ Normal } & \multicolumn{2}{|l|}{ Otimista } & \multicolumn{2}{|l|}{ Pessimista } \\
\hline & & $\mathrm{km}^{2}$ & $\%$ & $\mathrm{~km}^{2}$ & $\%$ & $\mathrm{~km}^{2}$ & $\%$ \\
\hline PSR & $\begin{array}{ll}\text { Plena } & \text { sem } \\
\text { restrição } & \end{array}$ & $4.305,44$ & 7,62 & 0,00 & 0,00 & 0,00 & 0,00 \\
\hline РCP & $\begin{array}{l}\text { Plena com } \\
\text { período chuvoso } \\
\text { prolongado }\end{array}$ & $5.794,71$ & 10,26 & 0,00 & 0,00 & 0,00 & 0,00 \\
\hline MEH & $\begin{array}{l}\text { Moderada por } \\
\text { excesso hídrico }\end{array}$ & 0,00 & 0,00 & 0,00 & 0,00 & 0,00 & 0,00 \\
\hline MDH & $\begin{array}{l}\text { Moderada por } \\
\text { deficiência } \\
\text { hídrica }\end{array}$ & $3.260,65$ & 5,77 & $4.081,20$ & 7,23 & 0,00 & 0,00 \\
\hline IDH & $\begin{array}{l}\text { Inapta } \quad \text { por } \\
\text { deficiência } \\
\text { hídrica }\end{array}$ & $43.106,44$ & 76,34 & $52.386,04$ & 92,77 & $56.467,24$ & 100 \\
\hline
\end{tabular}

Fonte: Elaborado pelos próprios autores

No cenário otimista, observa-se o deslocamento da classe moderada por deficiência hídrica $(\mathrm{MDH})$ para a região mais litoral do estado, ou seja, na mesorregião Mata Paraibana, passando a ocupar uma área de $4.081,20 \mathrm{~km}^{2}$, cerca de $7,23 \%$ da área total. E o aumento 
da classe inapta por restrição hídrica (IDH) para 52.386,04 km², correspondendo a cerca de $92,77 \%$ de sua área total.

Considerando o cenário de mudanças climáticas pessimista, a classe passa a abranger todo o estado, inviabilizando o cultivo de milho no estado. Em toda área do estado não foram observadas áreas com aptidão climática da classe Moderada por excesso hídrico $(\mathrm{MDH})$ em nenhum dos três cenários.

Em estudo da aptidão climática do milho no estado, FRANCISCO \& SANTOS (2018) considerando o cenário seco com $25 \%$ de probabilidade de chuvas, relatam que cerca de 96,55 \% da área total é considerada inapta por deficiência hídrica. BERGAMASCHI et al. (2004) constataram que pode haver redução de rendimento do milho, mesmo em anos climaticamente favoráveis, se o déficit hídrico ocorrer no período crítico, ou seja, da préfloração ao início de enchimento de grãos.

A EMBRAPA (2012), em estudo similar no estado de Alagoas, relata que em cenário regular de pluviometria o Agreste possui as melhores condições para o cultivo do milho em função da penetração das brisas terrestres e marítimas, que influenciam as chuvas na porção Leste e das elevações das encostas do Planalto da Borborema. Segundo o mesmo autor no cenário seco as possibilidades climáticas para o cultivo do milho são muito reduzidas devido à escassez hídrica, com $74 \%$ do Estado apresentando alto risco para o plantio de milho.

O mapeamento das classes de aptidões para as três culturas, ainda que no cenário otimista das mudanças climáticas, mostra um resultado preocupante para a agricultura no Estado da Paraíba. Se as emissões de carbono na atmosfera não forem minimizadas, o aumento da temperatura do ar permitirá que apenas a região litorânea do estado seja propícia à produção em regime de sequeiro. Em todas as demais regiões, será preciso alocar recursos hídricos para compor uma rede de irrigação suficiente para suportar toda a demanda de água. Considerando que a Paraíba não possui rios permanentes, a competição pela água fica evidente diante desse cenário.

É importante notar que medidas de mitigação podem ser tomadas com base nos Objetivos de Desenvolvimento Sustentável (ODS), o que inclui a ODS 2, que trata da meta de alcançar fome zero e uma agricultura sustentável, e a ODS 13, que inclui ações contra a mudança climática. Encontrando soluções que mitiguem os impactos da mudança climática, certamente irão reverter os impactos na produção agrícola no Estado da Paraíba. 


\section{CONCLUSÕES}

Em todo o estado não foi observado áreas com aptidão climática da classe Moderada por excesso hídrico (MDH) em nenhum dos três cenários. O cenário normal é o único que apresenta áreas com aptidão plena e plena com período chuvoso prologando para o cultivo das culturas.

No cenário otimista de mudanças climáticas ocorreu aumento drástico na área inapta por deficiência hídrica, e em apenas cerca de $7 \%$ da área do estado será possível os cultivos das culturas, porém, com moderada deficiência hídrica.

No cenário pessimista de mudanças climáticas, torna-se inviável o cultivo das culturas no estado. Essa inviabilidade é decorrente da drástica redução da disponibilidade hídrica que, à medida que este diminui, aumenta o déficit hídrico para a região.

Isto mostra o quanto as mudanças climáticas podem impactar economicamente o estado da Paraíba, devendo serem criadas políticas de mitigação.

\section{REFERÊNCIAS}

AESA - Agência Executiva de Gestão das Águas do Estado da Paraíba (2020)

Geoprocessamento GeoPortal AESA. http://siegrh.aesa.pb.gov.br:8080/aesa-sig/. Acessado em 26 de outubro de 2019.

ANDRADE JUNIOR, A. S.; NOLETO, D. H.; BASTOS, E. A.; MOURA, M. S. B.; ANJOS, J. C. R. Demanda hídrica da cana-de-açúcar, por balanço de energia, na microrregião de Teresina, Piauí. Agrometeoros, Passo Fundo, v. 25(1): 217-226, 2017.

BERGAMASCHI, H.; DALMAGO, G. A.; BERGONCI, J. I.; BIANCHI, C. A. M.; MÜLLER, A. G.; COMIRAN, F.; HECKLER, B. M. M. Distribuição hídrica no período crítico do milho e produção de grãos. Pesquisa Agropecuária Brasileira, Brasília, v. 39(9): 831-839, 2004.

CARVALHO, I. R.; KORCELSKI, C.; PELISSARI, G.; HANUS, A. D.; ROSA, G. M. Demanda hídrica das culturas de interesse agronômico. Enciclopédia biosfera, Centro Científico Conhecer Goiânia, v. 9(17): 969, 2013.

CONAB. Companhia Nacional de Abastecimento. Acompanhamento da safra brasileira de cana-de-açúcar. v. 6 - Safra 2019/20, n.2 - Segundo levantamento, agosto de 2019.

CONAB. Companhia Nacional de Abastecimento. Acompanhamento da safra brasileira de grãos. v. 6 - Safra 2018/19, n.11 - Décimo primeiro levantamento, agosto 2019. 
EMBRAPA. Empresa Brasileira de Pesquisa Agropecuária. Aptidão climática do Estado de Alagoas para culturas agrícolas. Relatório Técnico. Convênios SEAGRI-

AL/Embrapa Solos n.10200.04/0126-6 e 10200.09/0134-5. Recife: Embrapa Solos, 2012. 86p.

FRANCISCO, P. R. M.; MEDEIROS, R. M.; SANTOS, D.; MATOS, R. M. Classificação Climática de Köppen e Thornthwaite para o Estado da Paraíba. Revista Brasileira de Geografia Física, v. 8(4): 2015.

FRANCISCO, P. R. M.; SANTOS, D.; GUIMARÃES, C. L.; ARAUJO, S. R. D.; OLIVEIRA, F. P. Aptidão climática do milho (Zea mays L.) para o estado da Paraíba. Revista de Geografia, v. 34(1): 2017.

FRANCISCO, P. R. M.; SANTOS, D. Climatologia do Estado da Paraíba. 1a ed., Campina Grande-PB: EDUFCG. 2017. 10 p.

FRANCISCO, P. R. M; SANTOS, D. Aptidão Climática do Estado da Paraíba para as Principais Culturas Agrícolas. 1a ed., Campina Grande-PB: EPGRAF. 2018. p. 71-94.

IBGE. Instituto Brasileiro de Geografia e Estatística. Disponível em:

https://www.ibge.gov.br/cidades-e-estados/pb.html. Acesso em 20 de março de 2020.

Instituto Nacional de Pesquisas Espaciais (INPE). Uso de Cenários de Mudanças Climáticas Regionais em Estudos de Vulnerabilidade e Adaptação no Brasil e na América do Sul (GOF-UK-CPTEC). Relatório de Clima do INPE, ano 2, n. 4, p. 1-6, 2007.

JESUS, T. C. L.; SENNA, M. C. A.; CATALDI, M.; PAIVA, C. M.; FRANZ, B. 2017. Impacto do Aumento da Concentração Atmosférica de $\mathrm{CO}_{2}$ no Balanço Hídrico Climatológico do Cerrado. Revista Brasileira de Climatologia, v. 21: 313-326.

IPCC (2007) Climate Change - The physical science basis. Contribution of working group I to the fourth assessment Report of the IPCC. Cambridge University Press, Cambridge.

IPCC (2014) Climate Change 2014 - The Physical Science Basis. Working group I contribution to the fifth assessment report of the IPCC. Cambridge University Press, Cambridge.

MACHADO, T. S.; NEVES, S. M. A. S.; JUNIOR, S. S.; NEVES, R. J. 2017. Zoneamento Agroclimático do Melão na Região Sudoeste de Mato Grosso. Revista Brasileira de Climatologia, v. 20: 169-181.

MAPA. Ministério da Agricultura, Pecuária e Abastecimento. Secretaria de Política Agrícola. Portaria no 155, de 20 de julho de 2016. Disponível em: http://www.agricultura.gov.br. Acesso em: 3 de setembro de 2019.

MAPA. Ministério da Agricultura, Pecuária e Abastecimento. Secretaria de Política Agrícola. Portaria no 314, de 20 de setembro de 2010. Disponível em: http://www.agricultura.gov.br. Acesso em: 3 de setembro de 2019. 
MAPA. Ministério da Agricultura, Pecuária e Abastecimento. Secretaria de Política Agrícola. Portaria no 31, de $\mathbf{3 0}$ de abril de 2018. Disponível em:

http://www.agricultura.gov.br. Acesso em: 3 de setembro de 2019.

MATOS, R. M.; SILVA, J. A. S.; MEDEIROS, R. M. Aptidão climática para a cultura do feijão caupi do município de Barbalha - CE. Revista Brasileira de Agricultura Irrigada, v. 8(6): 422-431, 2014.

MATOS, R. M.; SILVA, P. F.; MEDEIROS, R. M.; SANTOS, B. D. B.; BARROS, A. S.; NETO, J. D.; SABOYA, L. M. F. Balanço hídrico climatológico normal e sequencial para o município de Barbalha - CE. Revista Brasileira de Geografia Física, v.13: 973-982, 2020.

MEDEIROS, R. M.; AZEVEDO, P. V.; SABOYA, L. M. F.; FRANCISCO, P. R. M. Classificação climática e zoneamento agroclimático para o município de Amarante - PI. Revista Brasileira de Agricultura Irrigada, v. 7(2): 170-180, 2013.

MINISTÉRIO DA AGRICULTURA, PECUÁRIA E ABASTECIMENTO (MAPA). Disponível em: http://www.agricultura.gov.br. Acesso em 23 de agosto de 2019.

MONTEIRO, J. E. B. A. Agrometeorologia dos cultivos: o fator meteorológico na produção agrícola. Brasília, DF: INMET, 2009.

NOBREGA, J. N; SANTOS C. A. C; GOMES O. M; BEZERRA, B. G; BRITO, J. I. B. Eventos extremos de precipitação nas mesorregiões da Paraíba e suas relações com a TSM dos oceanos tropicais. Revista Brasileira de Meteorologia, v. 29: 197-208, 2014.

OLIVEIRA, J. A. M.; OLIVEIRA, C. M. M. Balanço Hídrico Climatológico e Classificação Climática para o Município de Arinos - MG. Revista Brasileira de Agricultura Irrigada, v.12: 3021-3027, 2018.

PANDOLFO, C.; RICCE, W. S.; VIANNA, L. F. N.; MASSIGNAM, A. M. Zoneamento agroclimático do mirtilo irrigado em Santa Catarina. Agropecuária Catarinense, v.30: 8488, 2017.

PASSOS, M. L. V.; ZAMBRZYCKI, G. C.; PEREIRA, R. S. Balanço hídrico climatológico e classificação climática para o município de Balsas-MA. Scientia agraria, v. 18: 83-89, 2017.

PBMC, 2013: Contribuição do Grupo de Trabalho 2 ao Primeiro Relatório de Avaliação Nacional do Painel Brasileiro de Mudanças Climáticas. Sumário Executivo do GT2. Universidade Federal do Rio de Janeiro, Rio de Janeiro, RJ, Brasil, 10 p.

SILVA, S. C.; ASSAD, E. D.; LOBATO, E. J. V.; SANO, E. E.; STEINMETZ. S.; BEZERRA, H. S.; CUNHA, M. A. C.; SILVA, F. A. M. da. Zoneamento de agroclimático para o arroz de sequeiro no estado de Goiás. Brasilia-DF. 1995.

SNIDERMAN, J. M. K.; BROWN, J. R.; WOODHEAD, J. D.; KING, A. D.; GILLETT, N. P.; TOKARSKA, K. B.; LORBACHER, K.; DRYSDALE, R. N.; MEINSHAUSEN, M. Southern 
Hemisphere subtropical drying as a transient response to warming. Nature Climate Change, v. 9: 232-236, 2019.

SOUZA, D. C. F.; LIMA, I. S.; SANTANA, J. A.; ALMEIDA, A. Q.; GONZAGA, M. I. SILVA; SANTANA, J. F. Revista Brasileira de Agricultura Irrigada, v.12: 2338 - 2347, 2018.

THORNTHWAITE, C. W.; MATHER, J. R. The Water Balance. Publication in climatology. New Jersey: Drexel Institute of Technology, 1955. 104 p. 


\section{ABSTRACT}

The aim of the present work was to perform an agroclimatic zoning for the Paraíba State, Brazil taking as basis the climate change scenarios of the Intergovernmental Panel on Climate Change (IPCC), to assess the impact of water demand on the production of sugarcane, corn and rice, identifying and quantifying the areas that are suitable, unfit or that have some restrictions for these cultivations. The climatological water balance and the humidity index were determined using meteorological data of pluviometric precipitation and average air temperature of the six stations contained in the state, referring to the period from 1981 to 2018. To determine the agroclimatic ability of the crops, the humidity index ranges were used. It was found that in the normal scenario about $7.6 \%$ and $10 \%$ of the state's area has full suitability without restrictions and full suitability with prolonged rainy season, respectively, for the three crops. In an optimistic scenario, $7 \%$ of the state's area has moderate suitability due to water deficiency and $93 \%$ inept due to water deficiency. In a pessimistic scenario, the cultivation of crops in the state is not viable due to the drastic reduction in water availability for the region. It shows how much climate change can economically impact the Paraíba State, and mitigation policies must be created.

Keywords: Sugarcane. Rice. Maize. Water balance. Humidity index. Agroclimatic zoning.

\section{RESUMEN}

El objetivo del trabajo fue realizar una zonificación agroclimática para el estado de Paraíba con base en los escenarios de cambios climáticos del Panel Intergubernamental de Cambios Climáticos (IPCC), para evaluar el impacto de la demanda hídrica sobre la producción de caña de azúcar, maíz y arroz, identificando y cuantificando las áreas que están aptas, no aptas o que tienen algunas restricciones. El balance hídrico climatológico y el índice de humedad se determinaron utilizando dados meteorológicos de precipitación pluviométrica y temperatura media del aire de las seis estaciones contenidas en el estado, referidas al período de 1981 a 2018. Para determinar la idoneidad agroclimática de los cultivos fueron utilizadas las bandas del índice de humedad. Se constató que en el escenario normal alrededor del $7,6 \%$ y $10 \%$ del área del estado tiene plena aptitud sin restricciones y plena con temporada de lluvias prolongada, respectivamente, para los tres cultivos. En un escenario optimista, $7 \%$ del área del estado tiene aptitud moderada por deficiencia hídrica y $93 \%$ no apta por deficiencia hídrica. Ya en un escenario pesimista, sin embargo, se torna inviable el cultivo de las culturas en el estado debido a la drástica reducción de la disponibilidad hídrica para la región. Esto demuestra lo cuanto los cambios climáticos pueden impactar económicamente en el estado de Paraíba, donde deben ser criadas políticas de mitigación.

Palabras clave: Caña de azúcar. Arroz. Maíz. Balance hídrico. Índice de humedad. Zonificación climática. 


\section{LICENÇA DE USO}

Este é um artigo publicado em acesso aberto (Open Access) sob a licença Creative Commons Atribuição 4.0 Internacional (CC BY 4.0), que permite uso, distribuição e reprodução em qualquer meio, desde que o trabalho original seja corretamente citado. Mais informações em: http://creativecommons.org/licenses/by/4.0

\section{CONFLITO DE INTERESSES}

Os autores declaram que não há conflito de interesses neste trabalho.

\section{CONTRIBUIÇÕES AUTORAIS}

Amanda Fernandes Cândido: Responsável pela autoria de todo o texto.

Robson de Sousa Nascimento: Responsável pela análise de dados.

Valéria Peixoto Borges: Responsável pela análise de dados.

\section{FINANCIAMENTO}

Não houve financiamento

\section{COMO REFERENCIAR}

CÂNDIDO, Amanda Fernandes; NASCIMENTO, Robson de Sousa; BORGES, Valéria Peixoto. Impactos agroclimáticos para culturas agrícolas no estado da paraíba sob condições de mudanças climáticas. Revista Brasileira de Engenharia de Biossistemas (Tupã), v. 15, n. 1, p. 105-126, 2021. DOI:

http://dx.doi.org/10.18011/bioeng2021v15n1p105-126.

\section{RESPONSABILIBADE EDITORIAL}

Prof. Dr. Fernando Ferrari Putti ${ }^{1}$, Prof. Dr. Paulo Sérgio Barbosa dos Santos ${ }^{1}$, Prof. Dr. Eduardo Festozo Vicente ${ }^{1}$ e Prof. Dr. Diogo de Lucca Sartori ${ }^{1}$

1 Universidade Estadual Paulista "Júlio de Mesquita Filho", FCE - Faculdade de Ciências e Engenharia, Tupã, SP, Brasil. 